\title{
RESPONSABILIDADE SOCIAL CORPORATIVA E ÍNDICES DE SUSTENTABILIDADE: UM ESTUDO DOS ATIVOS TANGÍVEIS E INTANGÍVEIS À LUZ DA VISÃO BASEADA EM RECURSOS
}

Gabriel Paes de Almeida Joseph

Bacharel em Gestão Ambiental

Universidade de São Paulo - USP

São Paulo - São Paulo - Brasil

gabrieljowseph@gmail.com

Sylmara Lopes Francelino Gonçalves-Dias

Doutora em Ciência Ambiental e Administração de Empresas

Universidade de São Paulo - USP

São Paulo - São Paulo - Brasil

sgdias@usp.br

Annelise Vendramini Felsberg

Doutora em Administração

Centro de Estudos em Sustentabilidade da EAESP/FGV

São Paulo - São Paulo - Brasil

annelise.vendramini@fgv.br

\author{
Alexandre Toshiro Igari \\ Doutorado em Ecologia \\ Universidade de São Paulo - USP \\ São Paulo - São Paulo - Brasil \\ alexandre.igari@usp.br
}

\section{RESUMO}

A dinâmica multidimensional entre Responsabilidade Social Corporativa (RSC) e desempenho financeiro representa um desafio metodológico imenso para a consolidação teórica sobre o tema. Este artigo fundamenta-se na Visão Baseada em Recursos (VBR), entendendo que a incorporação da RSC é um elemento fundamental para a emergência e consolidação de ativos tangíveis e intangíveis das empresas. Realizou-se uma revisão sistemática da literatura acadêmica para entender se o engajamento em RSC, refletido na inserção e participação das empresas nos índices de sustentabilidade nas bolsas de valores, promoveria a melhoria de seus ativos. Os resultados revelaram contradições a respeito da relação entre a participação nos índices de sustentabilidade e a variação nos ativos corporativos. Um total de 15 casos indicaram resultados neutros (9) ou negativos (6) nos ativos. O ganho mais recorrente em ativos tangíveis foi o financeiro (24 casos), e em ativos intangíveis foi principalmente com relação à reputação das empresas (8 casos). Apesar de as predições teóricas conciliarem RSC e desempenho financeiro, uma parte substancial da literatura aponta resultados econômicos neutros ou negativos para a participação de empresas nos índices de sustentabilidade. Mesmo assim, além dos ganhos financeiros, foram identificadas associações entre a participação nos índices de sustentabilidade e melhorias em todas as categorias de ativos tangíveis e intangíveis previstas na literatura da VBR.

Palavras-chave: Ativos tangíveis e intangíveis; Djsi; Ftse4good; ISE- BM\&Fbovespa; Responsabilidade social corporativa; Visão baseada em recursos.

\section{CORPORATE SOCIAL RESPONSIBILITY AND SUSTAINABILITY INDEXES: A STUDY OF TANGIBLE AND INTANGIBLE ASSETS UNDER THE LIGHT OF THE RESOURCE BASED VIEW}

\begin{abstract}
The multidimensional dynamics between Corporate Social Responsibility (CSR) and financial performance represents a huge methodological challenge for theoretical consolidation on the theme. This paper is grounded on Resource Based View (RBV), and considers CSR incorporation as a essential element for emergence and consolidation of both corporate tangible and intangible assets. We conducted a systematic literature review to understand whether engagement on CSR, reflected on corporation insertion and participation in stock exchanges sustainability indexes, would promote assets improvement. Results revealed contradictions regarding the relationship between the engagement on sustainability indexes and variation on corporate assets. A total of 15 cases indicated neutral (9) or negative (6) outcomes on assets. The most recurrent gain on tangible assets was financial (24 cases), and intangible assets gains were mainly related to corporation reputation ( 8 cases). Despite theoretical predictions conciliate CSR and financial performance, a substantial part of the literature points out neutral or negative economic results from participation of companies in sustainability indexes. Beyond financial gains, results identified associations between participation in sustainability indexes and improvements in all categories of tangible and intangible assets predicted by RBV literature.
\end{abstract} Key words: Corporate social responsibility; Djsi; Ftse4Good; ISE- BM\&FBovespa; Resource based view; Tangible and intangible asset. 


\section{INTRODUÇÃO}

A dinâmica multidimensional entre Responsabilidade Social Corporativa e desempenho financeiro representa um desafio metodológico imenso para a consolidação teórica sobre o tema. $\mathrm{O}$ enquadramento teórico fundamentado na Visão Baseada em Recursos (VBR) parte do entendimento que a incorporação da RSC é um elemento fundamental para a emergência e consolidação de ativos corporativos intangíveis valorizados pelos stakeholders, e que este processo tem reflexo também nos outros ativos organizacionais (Branco \& Rodrigues, 2006; Hart 1995). Os ativos de uma empresa são entendidos pela VBR como os principais meios para alcançar um bom desempenho no mercado (Wernerfelt, 1984). Esta abordagem entende que faz mais sentido gerenciar bem os ativos internos na busca pela melhoria do desempenho do que procurar interferir nos fatores externos à corporação (Barney, 1991). O conceito de ativo pela VBR é mais alargado do que na abordagem contábil.

Não somente representam ativos corporativos os bens e direitos, tais como imóveis, equipamentos, veículos, estoques, recebíveis, patentes e propriedade intelectual, mas também elementos menos concretos, de domínio difuso, tais como reputação, habilidades intelectuais e sociais. Há então um gradiente entre ativos mais tangíveis, que são passíveis de aquisição, substituição ou imitação, e os mais intangíveis, constituídos pelas habilidades e capacidades cognitivas, comportamentais, culturais e sociais acumuladas pela organização ao longo de sua trajetória (Branco \& Rodrigues, 2006; Burlamaqui \& Proença, 2003).

$\mathrm{Na}$ perspectiva da VBR, são os ativos intangíveis que trazem vantagem competitiva duradoura às empresas, pois sua especificidade, complexidade e identidade com a trajetória histórica da organização dificultam a imitação e praticamente impedem a aquisição pelos concorrentes no mercado (Barney, 1991). Esta abordagem oferece contexto e elementos teóricos explicativos aplicáveis ao entendimento da dinâmica envolvida na incorporação da responsabilidade social na estratégia das empresas (McWilliams, Siegel \& Wright, 2006; Hart, 1995).

Nesse sentido, a adequada evidenciação das iniciativas de RSC é uma necessidade crescente, pois facultaria a todos atores sociais uma visão mais clara dos resultados obtidos ante os recursos utilizados. Os recursos naturais são evidentemente indispensáveis na produção de bens e serviços (Hart, 1995), o que faz da eficiência, parcimônia, precaução e prevenção os princípios orientadores fundamentais na relação entre a empresa e o ambiente natural. Entretanto, se vistos como recursos tangíveis, passíveis de aquisição e substituição, o domínio sobre os ativos ambientais não representaria vantagem competitiva duradoura à empresa (Barney, 1991). Por outro lado, a conservação ambiental e a responsabilidade social das empresas passam hoje pelo escrutínio ético e moral de seus stakeholders internos e externos, o que colocaria as empresas mais comprometidas com a RSC em posição de vantagem com relação à reputação e legitimação social de suas atividades (Orlitzky, Schmidt \& Rynes, 2003; Porter \& Van der Linde, 1995).

Assim, o engajamento das empresas à RSC e a consolidação da sua reputação e legitimidade, por um lado, podem resultar, em última instância, em desempenho financeiro (e aumento de ativo financeiro) mais atraente aos investidores (Orlitzky, Schmidt \& Rynes, 2003). Por outro, ativos reputacionais têm longo tempo de amadurecimento e são dependentes de investimentos de prazo mais curto, necessários ao desenvolvimento de processos e rotinas (ativos organizacionais), alterações nos equipamentos, produtos e insumos (ativos físicos e tecnológicos) e ao desenvolvimento de competências e habilidades individuais (ativos humanos) (Branco \& Rodrigues, 2006).

Na medida em que a incorporação da RSC nas estratégias corporativas ganha importância nas decisões dos stakeholders, as empresas mais engajadas encontram vantagem na seleção, contratação, manutenção e motivação de seus colaboradores, na atração de investidores e na relação com governo, agências setoriais, ONGs, fornecedores, credores e consumidores (Branco \& Rodrigues, 2006). O compromisso com a RSC contribuiria, então, para a construção e consolidação da reputação e legitimidade, que formam o amálgama historicamente moldado dos ativos sociais e 
humanos da organização. A complexidade social, a ambiguidade causal e a dependência da trajetória histórica fazem com que esses ativos intangíveis sejam dificilmente mimetizados pelos concorrentes, e contribuam, assim, para constituição de vantagens competitivas duradouras para as empresas (Branco \& Rodrigues, 2006).

Por outro lado, há poucas evidências concretas sobre os resultados dos projetos e iniciativas de RSC, o que pode ser parcialmente explicado pelo seu recorrente papel como mera ferramenta de publicidade, deixando em segundo plano o declarado propósito de representar um instrumento de transformação social (Cortes, Duarte, Gonçalves-Dias, 2014; Jones \& Jonas, 2011; Newell \& Frynas, 2007). Para contornar este desafio de identificar empresas alinhadas com os objetivos mais substantivos da RSC, este estudo tomou como ponto de partida a premissa que a inserção e participação nos índices de sustentabilidade nas bolsas de valores seriam uma sinalização razoável do compromisso estratégico com RSC, o que poderia então estar relacionado à melhoria de ativos tangíveis e intangíveis.

Os índices de sustentabilidade das bolsas de valores selecionam conjuntos de empresas por meio de parâmetros socioambientais, diferenciando-as no mercado aos acionistas que desejem utilizar a RSC como um critério de escolha dos seus portfólios de investimento (Bolsa de Valores, Mercadorias e Futuros [BM\&FBovespa], 2012). O investimento em empresas com boas práticas de sustentabilidade é denominado Investimento Socialmente Responsável (ISR) e apresenta um crescimento notável nos últimos anos (European Sustainable Investment Fora [Eurosif], 2012). Este crescimento teria como uma de suas explicações a ideia de que a incorporação da RSC e a participação em índices de sustentabilidade trariam ganhos em ativos tangíveis e intangíveis para as empresas, aumentando a liquidez e o valor de mercado de suas ações (BM\&FBovespa, 2012).

Busca-se, desta forma, contribuir para a elucidação da dinâmica multidimensional entre RSC e desempenho dos ativos por meio de uma revisão sistemática da literatura acadêmica. Este estudo ambiciona identificar se o conhecimento acadêmico acumulado corrobora a expectativa de que a inserção da RSC nas estratégias empresariais, refletida na participação nos índices de sustentabilidade dos mercados financeiros, está, de fato, relacionada ao incremento dos ativos corporativos, tanto tangíveis quanto intangíveis.

\section{REFERENCIAL TEÓRICO}

Esta seção organiza-se em três subtópicos que sintetizam os principais construtos teóricos necessários às reflexões posteriores, sem, no entanto, a ambição de apresentar uma revisão exaustiva a respeito da contribuição das distintas correntes teóricas que abordam cada tema.

\subsection{Visão baseada em recursos: ativos corporativos tangíveis e intangíveis}

Ações competitivas de uma empresa visam produzir efeitos positivos sobre o seu desempenho no mercado, colocando-a em posição de vantagem sobre suas concorrentes. Surge assim um ambiente de rivalidade, por meio de uma série de ações e respostas competitivas por parte

das empresas que atuam num mesmo mercado. É esperado que haja maior rivalidade quando as empresas utilizarem recursos mais semelhantes ou tiverem mercados em comum (Barney, 1991; Barney, 2001; Hitt, Ireland \& Hoskisson, 2008).

Os recursos corporativos podem ser categorizados em ativos tangíveis e intangíveis. Ativos tangíveis são aqueles passíveis de aquisição e substituição, tais como propriedades, instalações e estoques (Barney, 1991). Normalmente, ativos tangíveis não representam grande vantagem competitiva duradoura à empresa, na medida que podem ser adquiridos, substituídos ou imitados (Barney, 1991; Burlamaqui \& Proença, 2003; Russo \& Fouts, 1997). Hitt, Ireland \& Hoskisson (2008) e Branco \& Rodrigues (2006) categorizam os ativos tangíveis em quatro grupos: 
(i) Financeiros: dizem respeito à capacidade de financiamento e de gerar receita;

(ii) Organizacionais: referem-se à estrutura de planejamento, controle e coordenação;

(iii) Físicos: como instalações físicas, equipamentos e insumos;

(iv) Tecnológicos: como patentes, marcas registradas, direitos autorais e segredos comerciais, que são formas de tangibilizar o conhecimento.

Por outro lado, ativos intangíveis contribuem para vantagens competitivas mais duradouras (Barney, 1991; Branco \& Rodrigues, 2006; Burlamaqui \& Proença, 2003). A complexidade social, a ambiguidade causal e dependência da trajetória histórica fazem com que esses ativos intangíveis sejam dificilmente mimetizados pelos concorrentes, e contribuam assim para constituição de vantagens competitivas duradouras para as empresas (Barney, 1991; Branco \& Rodrigues, 2006). Hitt, Ireland \& Hoskisson (2008) e Branco \& Rodrigues (2006) categorizam os ativos intangíveis em três grupos:

(i) Inovações: conhecimento técnico e científico acumulado, capacidade e disposição a inovar;

(ii) Recursos humanos: competências cognitivas, comportamentais, culturais e sociais;

(iii) Reputação: percepções historicamente construídas dos stakeholders sobre a empresa.

As expectativas e percepções positivas sobre RSC têm influenciado no desenvolvimento dos ativos intangíveis, sobretudo na melhoria da reputação das empresas (Robinson, Kleffner \& Bertels, 2011; Searcy \& Elkhawas, 2012). Para a visão de gestão baseada em recursos, há uma inelasticidade temporal dos ativos intangíveis. Isso significa que eles são desenvolvidos por períodos de tempo tão extensos e por processos tão complexos que não podem ser rapidamente desenvolvidos, copiados ou comprados pelas concorrentes (Barney, 2001; Branco \& Rodrigues, 2006). Assim, a inelasticidade temporal de tais recursos no mercado faz com que as empresas que os detenham consigam estabelecer vantagens competitivas mais sólidas e duradouras (Barney, 1991; Branco \& Rodrigues, 2006).

Os recursos são ainda categorizados como valiosos ou raros. Os recursos valiosos são capazes de atribuir valor aos produtos/serviços oferecidos pela empresa. Eles destacam os diferenciais da empresa ou diminuem os custos de produção. Os recursos raros, por sua vez, são aqueles que podem ser adquiridos por apenas uma empresa (ou poucas). Se um recurso for valioso e raro, ele torna-se uma vantagem competitiva temporária. $\mathrm{O}$ que definirá se ela será duradoura é o custo que as concorrentes encontrariam para imitar ou substituir o recurso. Por fim, nenhum recurso é uma vantagem por si só, esta condição é dada pelo grau de controle e proteção que o ativo confere sobre as ameaças externas e pelo potencial de apropriação que permite sobre as oportunidades nos mercados em que a empresa atua (Barney, 1991; Branco \& Rodrigues, 2006; Russo \& Fouts, 1997).

Apesar de as visões convergirem no sentido de acreditar que as empresas têm uma função social a cumprir na sociedade, há discordância fundamental sobre a natureza das atribuições empresariais e também sobre quem se beneficiará com elas (Cortes, Duarte, Gonçalves-Dias, 2014). Assim, a oposição a qualquer tipo de envolvimento empresarial sistemático em questões socioambientais já é bastante antiga, e é nesse contexto que se insere o debate da empresa socialmente responsável.

\subsection{Responsabilidade social corporativa e a visão baseada em recursos}

O termo Responsabilidade Social Corporativa (RSC), em uma visão expandida, “[...]referese a toda e qualquer ação empreendida por uma empresa que contribua para a qualidade de vida da sociedade" (Ashley, 2002, p. 7). Embora essa definição possa parecer intuitivamente simples, há uma dinâmica e uma complexidade em torno disso. Existe um problema de semântica, uma vez que a interpretação do significado do termo RSC não é homogêneo. Nesse sentido, RSC pode assumir 
significações diferenciadas em contextos distintos que variam, desde o cumprimento das obrigações legais, até a intervenção em problemas sociais; passam pela responsabilidade com os produtos e chegam até aos compromissos com a sociedade e aos impactos ambientais, provocados pela atividade empresarial (Ashley, 2002; Carroll, 1999). Não há paradigma dominante de RSC e muito menos concordância sobre uma definição comum (Crane, Matten \& Spence, 2008; Matten \& Moon, 2008; McWilliams, Siegel \& Wright, 2006).

A RSC tem a desafiadora tarefa de harmonizar interesses privados dos acionistas a interesses coletivos de outros stakeholders, provendo resultados financeiros e socioambientais tanto em curto prazo quanto garantindo a perenidade de recursos da organização no longo prazo (Artiach et al., 2010). Ainda hoje, persistem as contradições em relação à RSC quanto à real responsabilidade na contenção de danos e externalidades por parte da empresa, assim como ao objetivo exclusivo de retorno financeiro (Devinney, 2009). De fato, a noção de RSC de que negócios têm responsabilidades para além do lucro continua ambígua e "essencialmente contestada" (Okoye, 2009).

Porter \& van der Linde (1995) já desafiavam a visão de que RSC representaria um ônus improdutivo para a empresa, afirmando que práticas de responsabilidade socioambiental levariam não apenas a benefícios sociais públicos, como também a benefícios corporativos privados. Neste sentido, a VBR caracteriza alguns caminhos pelos quais a incorporação da RSC pode levar a uma mudança nos ativos corporativos que compatibiliza os ganhos financeiros privados e os interesses socioambientais. O caminho mais evidente é o investimento de recursos financeiros em ativos tecnológicos, físicos e organizacionais, que são conduzidos por meio de ativos humanos e promovem aumento de ecoeficiência produtiva, reduzindo os custos relativos com insumos e disposição de resíduos. Este caminho virtuoso redundaria em aumento dos retornos financeiros privados e ganhos sociais com redução na exaustão do capital natural (Branco \& Rodrigues, 2006; Hart, 1995; Russo \& Fouts, 1997). Evidentemente os ganhos relativos em ecoeficência não garantem a redução absoluta dos insumos consumidos ou da poluição gerada, que é dependente do volume total de produção. Caso os aumentos de produção superem os ganhos com ecoeficiência, os impactos socioambientais negativos totais aumentarão (Farley \& Voinov, 2016).

Brzeszczynski \& McIntosh (2014) identificam como benefícios corporativos da RSC a melhora na reputação, o melhor relacionamento com instituições financeiras e investidores e acesso mais fácil a capital. Os ganhos reputacionais também conferem vantagens na seleção, contratação, manutenção e motivação dos colaboradores e na relação com governo, agências setoriais, ONGs, fornecedores e consumidores (Branco \& Rodrigues, 2006). O engajamento das empresas à RSC e a consolidação da sua reputação e legitimidade podem resultar, em última instância, em desempenho financeiro (e aumento de ativo financeiro) mais atraente aos investidores (Orlitzky, Schmidt \& Rynes, 2003). No entanto, Margolis \& Walsh (2003) analisam que, se as respostas das empresas aos problemas socioambientais forem avaliadas apenas em termos dos seus benefícios instrumentais para a empresa e seus acionistas, será difícil compreender os impactos da RSC na sociedade, principalmente sobre os supostos beneficiários dessas iniciativas.

Embora não haja entre os autores uma concordância sobre a RSC repercutir positivamente no valor de uma empresa, a verdade é que ela emerge das escolas de negócio como ferramenta de relações públicas, conforme lembram Newell \& Frynas (2007). Ela é utilizada, muitas vezes, para desviar e reduzir as críticas, capitalizando os bons resultados dessas ações, o que também é mencionado por Jackson \& Apostolakou (2010), Hart (2005) e Jenkins (2004). Dentre as motivações para o desenvolvimento de projetos de RSC, há organizações que apenas almejam bons resultados em rankings baseados nos índices de Investimento Socialmente Responsável (ISR), buscando utilizar esse resultado como estratégia de publicidade, até mesmo prejudicando a eficácia dos projetos desenvolvidos. Já Adam \& Shavit (2008), acreditam que a existência de rankings elaborados pelos índices de RSC acaba não incentivando as empresas excluídas desses índices a desenvolverem projetos socioambientais.

Revista de Gestão Social e Ambiental - RGSA, São Paulo, v. 12, n. 1, p. 73-88, jan./abr. 2018. 


\section{3 Índices de Sustentabilidade no Mercado Financeiro}

No intuito de reduzir a assimetria de informação entre empresas e investidores com interesse em RSC, as bolsas de valores conceberam os índices de sustentabilidade empresarial, que representam carteiras de investimento que reúnem as empresas com melhor desempenho em governança socioambiental (Marcondes \& Bacarji, 2010). A adoção de RSC em sua estratégia é o elemento imprescindível para a inclusão das empresas nesses índices de sustentabilidade. Sariannidis et al. (2010) definem Investimento Socialmente Responsável (ISR) como o processo que identifica e permite o investimento em companhias que implementam padrões de RSC. Para Sparkes (2002), ISR e RSC se espelham, servindo de motor para que as empresas gerem riqueza para a sociedade sob premissas sociais e ambientais.

O ISR representa um processo de investimento que busca conciliar os objetivos financeiros do investidor com suas preocupações e valores acerca do meio ambiente, da sociedade e de questões de governança (BM\&FBovespa, 2012). O século XXI experimentou um aumento na importância e intensidade nas discussões sobre ISR (Ortas, Burritt \& Moneva, 2013). Isso se deu, segundo os mesmos autores, pela ampliação das iniciativas de produção mais limpa e de padrões de consumo com maior preocupação socioambiental, pela demanda crescente por parte dos próprios investidores e pela pressão externa de ONGs e outros stakeholders em âmbito mundial.

A Eurosif (2012) também aponta uma maior demanda por parte dos investidores por transparência e clareza das práticas empresariais. O aumento da transparência reduziria as assimetrias de informação entre empresas e os potenciais investidores (Cavalcante, Bruni \& Costa, 2007; Branco \& Rodrigues, 2006). Clark \& Allen (2012) elencam ainda três principais fatores que justificariam ISR: diminuição de riscos futuros de catástrofes ambientais e de escândalos envolvendo violações da lei, preferência dos investidores por empresas engajadas em RSC e o desenvolvimento de vantagens competitivas fundamentadas em RSC. DiSegni, Huly \& Akron (2015) vão além e associam a responsabilidade social de uma empresa à sua capacidade de antecipar e gerenciar oportunidades e riscos socioambientais, tanto atuais e futuros.

Os índices de sustentabilidade estimulam a transparência nas empresas para, em contrapartida, fomentar oportunidades de investimento socioambientalmente orientado (Cunha \& Samanez, 2013). As metodologias utilizadas nos índices permitem a comparação entre empresas, auxiliando a tomada de decisão de investidores (Orsato et al., 2015). Este estudo tem como foco dois índices de sustentabilidade voltados para mercados globais, o pioneiro Dow Jones Sustainability Index (Djsi), criado em 1999, e o Ftse 4Good Index, desenvolvido em 2001 pelo Financial Times Stock Exchange Group (Ftse), assim como dois índices de bolsas de valores nacionais, o Johannesburg Stock Exchange Socially Responsible Investment Index (JSE SRI) lançado em 2004, e o Índice de Sustentabilidade Empresarial (ISE) da Bolsa de Valores de São Paulo, lançado em 2005 (figura 1).

\begin{tabular}{|c|c|c|c|}
\hline Nome & $\begin{array}{l}\text { Bolsa de } \\
\text { Valores }\end{array}$ & $\begin{array}{l}\text { Ano de } \\
\text { criação }\end{array}$ & Processo de seleção das empresas \\
\hline DJSI & $\begin{array}{l}\text { Nova } \\
\text { Iorque }\end{array}$ & 1999 & $\begin{array}{l}\text { Objetiva servir de referência para } \\
\text { investidores que valorizam aspectos Seleção das maiores empresas por setor } \\
\text { de sustentabilidade em seus do Standard \& Poor's Global Broad } \\
\text { portfólios. O índice tem diversas Market Index, sem exclusão de setores. } \\
\text { vertentes, sendo uma global e outras Estas empresas são convidadas a } \\
\text { divididas regionalmente entre responder um questionário posteriormente } \\
\text { Europa, América do Norte, Ásia do submetido à avaliação de sustentabilidade } \\
\text { Pacífico, Coréia, Austrália e países de corporativa pela empresa Robeco SAM. } \\
\text { mercados emergentes. }\end{array}$ \\
\hline
\end{tabular}

Revista de Gestão Social e Ambiental - RGSA, São Paulo, v. 12, n. 1, p. 73-88, jan./abr. 2018. 


\begin{tabular}{|c|c|c|c|}
\hline $\begin{array}{l}\text { FTSE } \\
\text { 4Good }\end{array}$ & Londres & 2001 & $\begin{array}{l}\text { sociais e de governança (ESG - própria empresa ou coletadas em suas } \\
\text { Environmental, Social and publicações referentes à RSC. Empresas } \\
\text { Governance) e reunir as empresas que deixam de atender aos requisitos são } \\
\text { com melhor desempenho contactadas e incentivadas a adotar as } \\
\text { socioambiental ao redor do mundo. práticas necessárias para manterem-se no } \\
\text { índice. }\end{array}$ \\
\hline JSE SRI & $\begin{array}{l}\text { Joanes- } \\
\text { burgo }\end{array}$ & 2004 & $\begin{array}{l}\text { Inspirado no Ftse4Good, identifica As empresas precisam, voluntariamente, } \\
\text { companhias sul-africanas com submeter um formulário de candidatura } \\
\text { melhores práticas de liderança em acompanhado de documentos exigidos } \\
\text { sustentabilidade, relevância social e pela JSE para comprovar seu } \\
\text { de governança. } \\
\text { compromisso com ESG. }\end{array}$ \\
\hline ISE & São Paulo & 2005 & 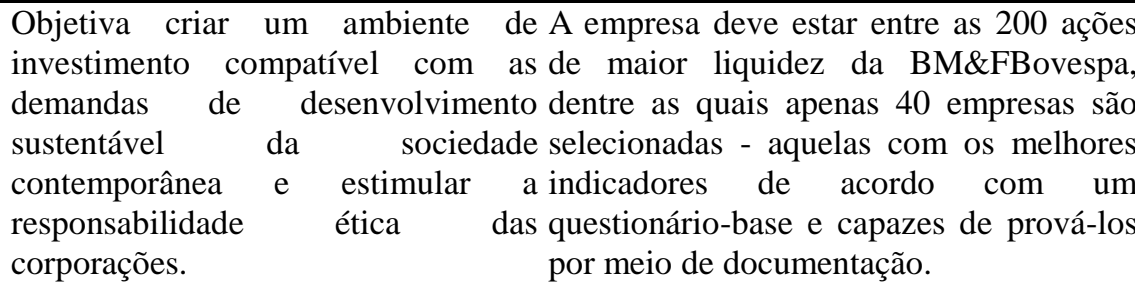 \\
\hline
\end{tabular}

Figura 1: Caracterização dos índices de sustentabilidade de bolsas de valores enfocados nesse estudo

Fonte: Elaboração dos autores (a partir dos websites dos índices)

Apesar do cenário de expansão, o fenômeno contemporâneo da RSC pode ser encarado como uma estratégia de nicho e não como uma mudança estrutural generalizada (Vogel, 2006). A RSC faz sentido pleno apenas para algumas firmas, em algumas áreas e sob circunstâncias determinadas. Também é irrealista imaginar que se possa exercer controles efetivos da RSC apenas por meio de instrumentos de regulação civil (Joseph \& Parkinson, 2002), como os ambiciosos índices de sustentabilidade das bolsas de valores. Sawani, Zain \& Darus (2010) verificaram que persistem problemas na transparência e confiabilidade das informações aos stakeholders, sendo ainda poucas as possibilidades para evidenciar, correta e equilibradamente, as ações socioambientais, o que contribui para a manutenção da assimetria informacional, consequentemente restringindo o alcance do controle social sobre os empreendimentos privados.

\section{PROCEDIMENTOS METODOLÓGICOS}

A metodologia deste estudo foi desenvolvida como uma pesquisa qualitativa de cunho descritivo, operacionalizada através de uma revisão sistemática de literatura do tipo "stand-alone". Okoli \& Schabram (2010) definem uma revisão "stand-alone" com aquela cujo único objetivo é revisar a literatura em um campo, independentemente de dados primários, e estruturam-na sistematicamente nas etapas descritas na figura 2.

\section{Etapa Descrição}

Definição de Identificação, dentre documentos científicos já publicados sobre o assunto na base de dados Propósito Scopus (www.scopus.com.br), a relação entre a inclusão ou participação de uma empresa em um índice de sustentabilidade do mercado financeiro e a variação de ativos tangíveis e intangíveis.

\begin{tabular}{ll}
\hline $\begin{array}{l}\text { Parâmetros } \\
\text { de busca }\end{array}$ & $\begin{array}{l}\text { Atendimento simultâneo a dois grupos de parâmetros lógicos de busca: (i) índices de } \\
\text { sustentabilidade em bolsas de valores ("Stock Exchange" or "Dow Jones" or "Ftse" or "JSE" or } \\
\text { "Bovespa"); e (ii) termos ligados à RSC ("sustainability" or "CSR" or "SRI" e "ESG"). }\end{array}$ \\
\hline $\begin{array}{l}\text { Triagem para } \\
\text { inclusão }\end{array}$ & $\begin{array}{l}\text { Seleção de inclusão a partir da avaliação preliminar de aderência dos títulos ao propósito } \\
\text { pesquisa. Foram descartados os documentos que notadamente não tinham aderência. Os casos } \\
\text { duvidosos foram conduzidos para a etapa seguinte. }\end{array}$
\end{tabular}


Triagem para Leitura dos resumos dos para identificar aderência dos objetivos do documento ao propósito exclusão desta revisão. Caso o resumo não fosse suficiente, lia-se também a introdução e a metodologia dos documentos.

Extração de Leitura integral dos documentos selecionados e extração de excertos de texto que incluíam dados evidências a serem analisadas e classificadas. Somente foram extraídos excertos a partir das seções "Resultados", "Discussão" e "Conclusões".

\begin{tabular}{ll}
\hline $\begin{array}{l}\text { Síntese dos } \\
\text { estudos }\end{array}$ & $\begin{array}{l}\text { Análise qualitativa e classificação das evidências nas categorias delimitadas a partir do } \\
\text { referencial teórico: "melhoria nos ativos tangíveis" (financeiros, organizacionais, físicos ou } \\
\text { tecnológicos), "melhoria nos ativos intangíveis" (inovação, recursos humanos ou reputação) ou }\end{array}$ \\
& "sem melhoria" (neutros e negativos). \\
\hline Redação & Consolidação e síntese dos resultados.
\end{tabular}

Figura 2: Descrição das etapas para realização da revisão sistemática da literatura

Fonte: Elaboração dos autores

A busca original na base de dados Scopus, realizada em 4 de fevereiro de 2016, retornou 324 documentos, incluindo artigos (predominantemente), capítulos de livros e artigos de conferências. O total remanescente após a triagem para inclusão foi de 105 documentos. Após a leitura dos resumos para a triagem de exclusão, o total de documentos selecionados para a extração de dados foi de 52 documentos. Dos 52 documentos selecionados, 5 foram excluídos após a leitura integral dos textos. Dois artigos não puderam ser acessados. Desta forma, este estudo fundamentou-se em um conjunto de 45 documentos.

\section{RESULTADOS E DISCUSSÃO}

A revisão da literatura aqui empreendida mostrou que predominam estudos sobre o Dow Jones Sustainability Index - Djsi (Tab. 1), comparativamente aos outros índices, o que pode ser explicado pelo pioneirismo do Djsi e pela relevância internacional da Bolsa de Nova Iorque, que organiza o índice. Há também uma clara predominância de melhoria de desempenho em ativos financeiros (Tab. 1), totalizando 24 registros, com relação às melhorias nos demais ativos, que totalizaram 14 ocorrências. Entre os ativos intangíveis, foi mais recorrente a melhoria de reputação, com oito registros. Entretanto, a revisão apresenta um substancial número de resultados neutros (nove registros) ou mesmo negativos (seis registros) quanto à participação das empresas nos índices de sustentabilidade analisados.

Tabela 1: Número de registros que relacionam a participação das empresas nos índices de sustentabilidade do mercado financeiro (colunas) à melhoria de ativos tangíveis e intangíveis, ou ainda a resultados neutros e negativos (linhas)

\begin{tabular}{|c|c|c|c|c|c|c|c|}
\hline $\begin{array}{l}\text { Categorização } \\
\text { tangíveis e inta }\end{array}$ & $\begin{array}{l}\text { dos aspectos } \\
\text { ngíveis }\end{array}$ & DJSI & FTSE & JSE & ISE & $\begin{array}{l}\text { Outros } \\
\text { Índices }\end{array}$ & Total \\
\hline & Financeiros & 18 & 1 & - & 2 & 3 & 24 \\
\hline Melhoria em & Organizacionais & 2 & - & - & - & - & 2 \\
\hline ativos tangíveis & Físicos & 1 & - & - & - & - & 1 \\
\hline & Tecnológicos & - & - & - & - & - & $\mathbf{0}$ \\
\hline Melhoria em & Inovações & 1 & - & - & - & - & 1 \\
\hline ativos & Recursos Humanos & 2 & - & - & - & - & 2 \\
\hline intangíveis & Reputação & 6 & - & - & 2 & - & 8 \\
\hline Sem Molhoria & Neutros & 5 & 1 & 1 & 1 & 1 & 9 \\
\hline sem Mieinoria & Negativos & 3 & - & 1 & 1 & 1 & 6 \\
\hline
\end{tabular}

Fonte: Elaboração própria

Dentre os resultados negativos, que alimentam a controvérsia a respeito dos resultados financeiros da incorporação de estratégias direcionadas à RSC, López, García \& Rodríguez (2007) 
encontraram uma correlação negativa entre os ativos financeiros e a presença da empresa no Djsi, ao menos nos primeiros anos de participação. Também avaliando o Djsi, Cheung (2011) obteve resultados negativos, observando que os investidores valorizam práticas RSC apenas temporariamente.

Posteriormente, Cheung \& Roca (2013) encontraram retornos financeiros negativos tanto para empresas que eram incluídas quanto excluídas do Djsi - Asia Pacific, que é uma vertente regional do índice. Estes resultados são contrastantes com os de Consolandi et al. (2009), que evidenciam ganhos e perdas assimétricos com relação à inclusão e exclusão no Djsi, pois ocorrem prejuízos muito mais intensos para empresas que são excluídas do Djsi do que ganhos com a inclusão no índice.

A contradição neste tema aprofunda-se quando Clark \& Allen (2012) refutam os resultados negativos encontrados no estudo de Cheung (2011), ao replicarem a análise no Djsi utilizando diferentes formas de avaliação. Clark \& Allen (2012) afirmam que Cheung (2011) utilizou formas de avaliação muito específicas para finanças, o que pode ter trazido viés aos resultados. Assim, Clark \& Allen (2012) identificaram resultados de melhora nos ativos financeiros, além de avaliarem que os investidores têm atitudes mais positivas diante de empresas participantes de índices de sustentabilidade (Tab. 2).

Robinson, Kleffner \& Bertels (2011) corroboram os resultados de Clark \& Allen (2012) quanto à melhoria dos ativos financeiros, identificando ainda um aumento gradual no valor das ações de empresas que entram no Djsi durante os primeiros meses de participação, principalmente em razão de ganho de ativos reputacionais (Tab. 2). Entretanto, ao contrário de Consolandi et al. (2009), Robinson, Kleffner \& Bertels (2011) afirmam que a saída do índice não apresenta grandes perdas para as empresas. Os ganhos reputacionais identificados por Robinson, Kleffner \& Bertels (2011) são também confirmados por Searcy \& Elkhawas (2012) para empresas canadenses que ingressaram no Djsi (Tab. 2). Além disso, as empresas canadenses também obtiveram ganhos em ativos organizacionais ao espelhar sua governança com as outras empresas do índice (Tab.2).

Tabela 2: Excertos de argumentos que fundamentam a categorização como aspectos de melhoria em ativos tangíveis, intangíveis ou ainda como neutros ou negativos.

Categorização dos

aspectos tangíveis e Excertos $\quad$ Referência

intangíveis

"Em suma, os resultados indicam que empresas orientadas pela sustentabilidade foram melhores em controlar seus custos e elas também aparentaram ser melhores em geração de lucro do que as companhias de energia mais convencionais. E em relação aos

Pätäri, et al. (2012)

Financeiros valores de mercado, os resultados claramente apontaram que os valores de mercado foram maiores entre as empresas do Djsi" "Os resultados corroboram fortemente a hipótese de que o mercado de investimentos tende a atribuir razões de valoração maiores a empresas incluídas no Djsi do que seus concorrentes não-Djsi."

"Outro tema se focou em ajudar as corporações a identificar áreas de melhoria futura. Uma empresa de materiais básicos disse que

Organizacionais uma assessoria de terceira-parte ajuda a dar feedback que identifica Searcy \& Elkhawas deficiências e áreas para melhoria. (...) Mais adiante, um (2012) especialista no setor industrial disse que a submissão ao Djsi ajuda a melhorar processos internos de relatórios e a fomentar inovação"

$\mathrm{O}$ artigo não aponta textualmente o ganho de ativos físicos, mas os

Físicos resultados demonstram quantitativamente o aumento de ativos da Yu \& Zhao (2015) empresa por meio do investimento em bens de capital (Capex). 
“(...)Empresas incluídas no Djsi-AP (Ásia do Pacífico) ganham uma abordagem ecoeficiente não apenas pela economia de custos associada à produção mais limpa e atividades ecoeficientes, mas Inovações também por meio de ganho de vantagem competitiva por ser um first-mover e reduzindo risco por diversos motivos: (...) d) usando

Ortas, Burritt \&

Moneva (2013) P\&D como uma maneira de aprender sobre o campo da sustentabilidade ambiental e empresarial."

"Nós, portanto, concluímos que companhias Sres empregam um

Recursos Humanos número maior de funcionários e interagem com um nível maior de recursos humanos, comparadas a outras companhias na mesma indústria e setor."

“(...) Mais adiante, a análise de regressão multivariada indica que esse aumento de valor é devido a efeitos reputacionais,

Robinson, Kleffner \& diferentemente do efeito de uma firma ser adicionada a um grande Bertels (2011)

Reputação índice de ações"

"Muitos dos benefícios citados também se focaram em benefícios reputacionais. Benefícios como 'direitos de se gabar' e

Searcy \& Elkhawas aprimoramento da marca foram citados por companhias no setor (2012) financeiro."

\begin{tabular}{|c|c|c|}
\hline Neutros & $\begin{array}{l}\text { "A análise microeconométrica implica efeitos insignificantes na } \\
\text { inclusão ao Djsi World ao retorno sobre os ativos de (empresas do) } \\
\text { Reino Unido e Irlanda. Em contraste, o impacto é positivo em } \\
\text { outros países europeus." } \\
\text { "Assim sendo, ainda não há impacto positivo consolidado - ou, ao } \\
\text { menos, não provado estatisticamente - na performance no mercado } \\
\text { de capitais de empresas de óleo causado pela adoção de uma } \\
\text { postura socioambiental proativa. Mais especificamente, exceto pela } \\
\text { Petrobras e Suncor, a inclusão no ou exclusão do Djsi não teve } \\
\text { relação significante com a variação no preço das ações." }\end{array}$ & Schaeffer et al. (2012) \\
\hline Negativos & $\begin{array}{l}\text { "Nós também observamos que o ISE teve uma performance muito } \\
\text { similar à do IBovespa, ainda que o ISE tenha demonstrado uma } \\
\text { recuperação pior durante e após a crise financeira de } 2008 . " \\
\text { "Resultados indicam que a comunicação da inclusão ou } \\
\text { manutenção em um índice de sustentabilidade tem efeitos diferentes } \\
\text { dependendo do setor analisado. Os setores de bens de consumo e } \\
\text { serviços apresentam Resultados Anormais (AR) positivos e } \\
\text { significantes, enquanto os setores de petróleo e indústrias } \\
\text { apresentam resultados anormais negativos e significantes." } \\
\text { "Isso confirma os resultados de muitos estudos anteriormente, que } \\
\text { ISRs não levam uma performance melhor significante comparados } \\
\text { a benchmarks convencionais. No entanto, os resultados indicaram } \\
\text { que o índice SRI teve uma performance significativamente abaixo } \\
\text { da dos ETFs durante o período de declínio econômico." }\end{array}$ & $\begin{array}{l}\text { Cunha \& Samanez } \\
\text { (2013) } \\
\text { Callado-Muñoz \& } \\
\text { Utrero-González (2008) }\end{array}$ \\
\hline
\end{tabular}
Fonte: Elaboração própria

Alguns resultados relatados são considerados negativos em razão da valorização inferior, comparativamente aos índices ou carteiras de ações convencionais na mesma bolsa de valores. Marozva (2014) compara o desempenho do JSE SRI Index com o de vários Fundos Transacionados em Bolsa (ETFs - Exchange-Traded Funds) que estimaram o desempenho do JSE All Share Index (Tab. 2). Os resultados mostram que o desempenho de índices de sustentabilidade não seria superior ao dos índices convencionais. Haveria, inclusive, indicações de que os índices de sustentabilidade tiveram desempenhos piores do que os ETFs nos períodos de declínio econômico e evidências de que os ETFs superaram o desempenho do JSE SRI Index em vários momentos durante o crescimento econômico também.

Mesmo estudos em horizontes temporais mais longos não equacionam de forma mais robusta a questão do desempenho dos ativos financeiros frente às iniciativas de incorporação de RSC na gestão. Swidler \& Crutchley (2009) realizaram um estudo de nove anos acerca de empresas 
estadounidenses que participaram do Dow Jones Global Sustainability Index. Os autores enumeram uma série de casos em que empresas participantes do índice não obtiveram sucesso, indo à falência ou se envolvendo em escândalos. Ainda assim, eles observam retornos maiores para as empresas participantes do índice do que para outras empresas de grande capitalização no mercado durante o período estudado. Entretanto, o desempenho não foi uniforme, pois algumas ações sofreram quedas bruscas após a inclusão no índice e, nos quatro anos finais da análise, os desempenhos de empresas participantes e não participantes foram muito semelhantes.

Pätäri et al. (2012) também identificam resultados positivos para os ativos financeiros de empresas participantes do Dow Jones Sustainability Index (Tab. 2), mas, assim como Swidler \& Crutchley (2009), entendem que empresas não participantes conseguem alcançar resultados semelhantes mesmo sem estar nos índices. Skare \& Golja (2012), por outro lado, arriscam dizer que a probabilidade de alcançar retornos financeiros positivos é seis vezes maior para empresas com boas práticas socioambientais (que os autores atribuem à participação no DJSI) do que para empresas sem esse compromisso.

É relevante ressalvar que a associação entre a participação nos índices de sustentabilidade e a melhoria nos ativos tangíveis e intangíveis, em muitos casos, pode ser simplesmente efeito de covariações em razão de fatores exógenos. Artiach et al. (2010) encontraram uma série de resultados positivos associados à participação no Djsi. Entretanto, tamanho e capacidade de crescimento foram duas características positivamente associadas às melhorias de desempenho em todas as empresas analisadas pelo estudo. Assim, os autores correm o risco de terem estabelecido uma associação equivocada dos resultados positivos com a participação no Djsi, quando, na verdade, podem estar associados primariamente ao porte e potencial de crescimento das empresas.

Outro caso similar é apresentado por Schaeffer et al. (2012), que estudaram o desempenho de empresas petrolíferas que foram incluídas no Djsi entre 2004 e 2011 (Tab. 2). Os autores apontam melhorias na reputação de uma das sete empresas estudadas e um retorno financeiro bastante acentuado para outra. No entanto, eles creditam tal retorno financeiro a especulações acerca de novas jazidas encontradas durante o período analisado. Ainda assim, os autores acreditam que a ausência de práticas RSC para empresas petrolíferas pode erodir seus retornos financeiros, bem como destruir sua reputação no longo prazo. Tsoutsoura (2004) ressalta a dificuldade em medir a causalidade entre a adoção de práticas RSC e a melhoria de desempenho da empresa, até mesmo conceitualmente, porque as práticas RSC estariam integradas às práticas do negócio, o que dificultaria a medição de seus resultados separadamente.

Destacando os resultados para o Índice de Sustentabilidade Empresarial - ISE da BM\&FBovespa, Lourenço \& Castelo Branco (2013) encontraram retornos positivos no que diz respeito aos ativos financeiros, bem como organizacionais, físicos, e reputação das empresas participantes. Carvalhal \& Tavares (2013) chegaram às mesmas conclusões, relatando benefícios nos ativos financeiros, organizacionais, melhorias na reputação e ainda de recursos humanos em empresas participantes do ISE. Lameira et al. (2013), por um lado, encontraram resultados semelhantes, mas com maior ênfase no aumento de retornos financeiros para as empresas participantes. Por outro, Cunha \& Samanez (2013) evidenciaram quedas nos retornos financeiros associados à participação no ISE, apesar de também encontrarem resultados positivos em ativos organizacionais e melhorias na reputação, o que indica que a investigação sobre o ISE também não está livre da controvérsia a respeito dos efeitos financeiros da participação nos índices de sustentabilidade dos mercados financeiros.

\section{CONSIDERAÇÕES FINAIS}

Este estudo investigou a proposição de que a incorporação da Responsabilidade Social Corporativa nas estratégias empresariais, refletida na participação de empresas nos índices de sustentabilidade nas bolsas de valores, promoveria o desenvolvimento de ativos tangíveis e intangíveis. Os resultados da revisão sistemática revelaram contradições a respeito dos resultados 
corporativos da RSC. Foram encontrados artigos que realizaram estudos bastante semelhantes, investigando o mesmo mercado regional, mas que apresentaram resultados antagônicos.

Ainda assim, a maior parte dos estudos já publicados sobre o assunto encontrou resultados positivos para a participação em índices de sustentabilidade. O ganho mais recorrente em ativos tangíveis foi o financeiro, ao passo que a melhoria mais frequente quanto aos ativos intangíveis foi com relação à reputação das empresas, o que corrobora as expectativas delineadas a partir da Visão Baseada em Recursos (VBR). No entanto, é preciso esclarecer que a maioria dos estudos se propôs, desde o começo, a analisar apenas os retornos financeiros das empresas, o que certamente introduz um viés nos resultados da revisão sistemática. Mesmo assim, além dos ganhos financeiros, foram identificadas associações entre a participação nos índices de sustentabilidade e melhorias em todas as categorias de ativos tangíveis e intangíveis previstas na literatura da VBR.

Este estudo contribuiu para consolidar o conhecimento acumulado na literatura científica a respeito da relação entre resultados corporativos e a incorporação de RSC às estratégias de empresas que passaram a participar de índices de sustentabilidade de mercados financeiros. Apesar das predições teóricas conciliarem RSC e desempenho financeiro, uma parte substancial da literatura aponta resultados econômicos neutros ou negativos para a participação de empresas nos índices de sustentabilidade.

A complexidade e recursividade das relações entre os ativos corporativos no que tange à incorporação da RSC à estratégia das empresas não permite, com base nos resultados deste estudo, avançar mais sobre a elucidação das relações de causalidade. Os resultados dos artigos são pautados em constatações de correlações ou mesmo de colinearidade entre as variáveis, que demandariam comparativos com controles, estudos de caso históricos ou mesmo um grande número de observações quantitativas independentes para inferir as relações de causalidade que orientam o fenômeno estudado.

Porém, o imperativo lógico da RSC pode ser (e é) facilmente acusado de entrar em contradição com alguns pressupostos fundamentais da teoria econômica clássica e neoclássica, tais como os direitos de propriedade, a separação entre o que é atribuição do Estado ou da iniciativa privada, e a dinâmica natural do mercado. É nesse sentido que a atuação social das empresas demanda a análise do risco de que "[...] os interesses corporativos apropriem-se dos interesses públicos, por vezes resultando nos chamados programas corporativos de bem-estar" (Boje, 2002, p. 17). Enfatiza-se, assim, a importância de uma reflexão crítica, onde a dimensão pública do Estado e da sociedade civil participem da construção desse campo organizacional, promovendo um equilíbrio maior de interesses.

\section{AGRADECIMENTOS}

Os autores agradecem os comentários e as sugestões dos revisores anônimos, que contribuíram, sobremaneira, para o refinamento da versão inicial deste artigo. Ressalta-se que as reflexões, opiniões e eventuais omissões ou equívocos são de responsabilidade exclusiva dos autores.

\section{REFERÊNCIAS}

Adam, A. M., \& Shavit, T. (2008). How can a ratings-based method for assessing corporate social responsibility (CSR) provide an incentive to firms excluded from socially responsible investment indices to invest in CSR?. Journal of Business Ethics, 82(4), 899-905.

Artiach, T., Lee, D., Nelson, D., \& Walker, J. (2010). The determinants of corporate sustainability performance. Accounting and Finance, 50(2), 31-51.

Ashley, P. A. (2002). Ética e responsabilidade social nos negócios. São Paulo: Saraiva, 153. BM\&FBovespa (2012). O Valor do ISE: principais estudos e as perspectivas dos investidores. São Paulo, SP: Bolsa de Valores, Mercadorias e Futuros. 
Barney, J. B. (1991) Firm resources and sustained competitive advantage. Journal of Management. 17(1), 99-120.

Barney, J. B. (2001). Resource-based theories of competitive advantage: a ten-year retrospective on the resource-based view. Journal of Management. 27, 643-650.

Boje, D. (2002). Resistência carnavalesca ao espetáculo global. Revista de Administração de Empresas, 42(4), 1-18.

Branco, M. C., \& Rodrigues, L. L. (2006). Corporate social responsibility and resource-based perspectives. Journal of business Ethics, 69(2), 111-132.

Brzeszczynski J., \& McIntosh, G. (2014). Performance of portfolios composed of British SRI stocks. Journal of Business Ethics, 120, 335-362.

Burlamaqui, L., \& Proença, A. (2003). Inovação, recursos e comprometimento: em direção a uma teoria estratégica da firma. Revista Brasileira de Inovação, 2(1), 79-111.

Callado-Muñoz, F. J., \& Utrero-González, N. (2008). Do investors react to environmental friendly news? An analysis for Spanish capital market. Corporate Ownership and Control, 5(2), 315-321.

Carroll, A. B. (1999). Corporate social responsibility: evolution of a definitional construct. Business Society. 28(3), 268-295.

Carvalhal, A., \& Tavares, E. (2013). Does social responsibility enhance firm value and return in Brazil? Corporate Ownership \& Control, 15(2), 253-257.

Cavalcante, L. R. M. T., Bruni, A. L., \& Costa, F. J. M. (2007) Sustentabilidade empresarial e desempenho corporativo: uma análise do Mercado Brasileiro de Ações. Artigo apresentado no Encontro da Anpad, 31,. Rio de Janeiro, RJ.

Cheung, A. W. K. (2011). Do stock investors value corporate sustainability? Evidence from an event study. Journal of Business Ethics, 99(2), 145-165.

Cheung, A. W. K., \& Roca, E. (2013) The effect on price, liquidity and risk when stocks are added to and deleted from a sustainability index: evidence from the Asia Pacific context. Journal of Asian Economics, 24, 51-65.

Clark, T. S., \& Allen, D. S. (2012). Shareholder value from sustainability leadership: comparing valuation ratios whithin industry groups. International Research Journal of Finance and Economics, 89, 108-117.

Consolandi, C., Jaiswal-Dale, A., Poggiani, E., \& Vercelli, A. (2009). Global standards and ethical stock indexes: the case of the Dow Jones sustainability stoxx index. Journal of Business Ethics. 87(1), 185-197.

Cortes, P.L., Duarte, J.R.C., Gonçalves-Dias, S.L.F. (2014). Development of corporate social responsibility projects in Angola. Social Responsibility Journal, 10 (2), 268-281.

Crane, A., Matten, D., \& Spence, L. J. (Eds.). (2008). The Oxford handbook of corporate social responsibility. Oxford: Oxford University Press. 
Cunha, F. A. F. S., \& Samanez, C. P. (2013). Performance analysis of sustainable investments in the Brazilian stock market: a study about the Corporate Sustainability Index (ISE). Journal of Business Ethics. 117(1), 19-36.

Devinney, T. M. (2009). Is the socially responsible corporation a myth? The good, the bad, and the ugly of corporate social responsibility. Academy of Management Perspectives. 2 (23), 44-56.

Disegni, D. M., Huly, M., \& Akron, S. (2015) Corporate social responsibility, environmental leadership and financial performance. Social Responsibility Journal, 11(1), 131-148.

European SRI Study 2012 (Estudo da Eurosif). (2012). Bruxelas: Bélgica. European Sustainable Investment Fora.

Farley, J., \& Voinov, A. (2016). Economics, socio-ecological resilience and ecosystem services. Journal of environmental management, 183, 389-398.

Hart, S. L.(1995) A natural-resource-based view of the firm. (1995). Academy of Management Review, 20(4), 986-1014.

Hart, S. L. (2005). Capitalism at the crossroads: the unlimited business opportunities in solving the world's most difficult problems. Pearson Education.

Hitt, M. A., Ireland, R. D., \& Hoskisson, R. E. (2008). Administração estratégica. Tradução da $7^{a}$ edição norte-americana. São Paulo: Cengane Learning.

Jackson, G., \& Apostolakou, A. (2010). Corporate social responsibility in Western Europe: an institutional mirror or substitute?. Journal of Business Ethics, 94(3), 371-394.

Jenkins, H. (2004). Corporate social responsibility and the mining industry: conflicts and constructs. Corporate Social Responsibility and Environmental Management, 11(1), 23-34.

Jones III, A., \& Jonas, G. A. (2011). Corporate social responsibility reporting: the growing need for input from the accounting profession. The CPA journal, 81(2), 65-71.

Joseph, E., \& Parkinson, J. (2002). Confronting the critics. New Academy Review, 1(1).

Lameira, V. J., Ness Jr, W. L., Quelhas, O. L. G., \& Pereira, R. G. (2013). Sustentabilidade, valor, desempenho e risco no mercado de capitais brasileiro. Revista Brasileira de Gestão de Negócios, 15(42), 76-90.

López, M. V., García, A., \& Rodríguez, L. (2007) Sustainable development and corporate performance: a study based on the Dow Jones Sustainability Index. Journal of Business Ethics, 75(3), 285-300.

Lourenço, I. C., \& Castelo Branco, M. (2013). Determinants of corporate sustainability performance in emerging markets: the Brazilian case. Journal of Cleaner Production, 57, 134-141.

Marcondes, A. W., \& Bacarji, C. D. (2010). ISE - sustentabilidade no mercado de capitais. São Paulo: Report Editora. 
Margolis, J. D., \& Walsh, J. P. (2003). Misery loves companies: rethinking social initiatives by business. Administrative science quarterly, 48(2), 268-305.

Marozva, G. (2014). The performance of socially responsible investment funds: evidence from Johannesburg Stock Exchange. Corporate Ownership \& Control, 11(4a), 143-152.

Matten, D., \& Moon, J. (2008). "Implicit" and "explicit” CSR: a conceptual framework for a comparative understanding of corporate social responsibility. Academy of management Review, 33(2), 404-424.

McWilliams, A., Siegel, D. S., \& Wright, P. M. (2006). Corporate social responsibility: strategic implications. Journal of management studies, 43(1), 1-18

Newell, P., \& Frynas, J. G. (2007). Beyond CSR? Business, poverty and social justice: an introduction. Third world quarterly, 28(4), 669-681.

Okoli, C., \& Schabram, K. A. (2010). Guide to conducting a systematic literature review of information systems research. Sprouts: Working Papers on Information Systems, 10(26). Recuperado de http://sprouts.aisnet.org/10-26. Acesso em: 20 dez.2017.

Okoye, A. (2009). Theorising corporate social responsibility as an essentially contested concept: is a definition necessary? Journal of Business Ethics, 89(4), 613-627.

Orlitzky, M., Schmidt, F., \& Rynes, S. (2003). Corporate social and financial performance: a metaanalysis. Organization Studies, 24(3), 403-441.

Ortas, E., Burritt, R. L., \& Moneva, J. M. (2013) Socially responsible investment and cleaner production in the Asia Pacific: does it pay to be good? Journal of Cleaner Production, 52, 272-280.

Orsato, R. J., Garcia, A. Mendes-Da-Silva, W. Simonetti, R., \& Monzoni, M. (2015) Sustainability indexes: why join in? A study of the 'Corporate Sustainability index (ISE)' in Brazil. Journal of Cleaner Production, 96, 161-170.

Pätäri, S., Jantunen, A., Kyläheiko, K., \& Sandström, J. (2012). Does sustainable development foster value creation? Empirical evidence from the global energy industry. Corporate Social Responsibility and Environmental Management, 19(6), 317-326.

Porter, M. E, \& van der Linde, C. (1995) Green and competitive: ending the stalemate. Harvard Business Review, 73(5), 120-134.

Robinson, M., Kleffner, A., \& Bertels, S. (2011). Signaling sustainability leadership: empirical evidence of the value of Djsi membership. Journal of Business Ethics, 101(3), 493-505.

Russo, M. V., \& Fouts, P. A. (1997). A resource-based perspective on corporate environmental performance and profitability. Academy of management Journal, 40(3), 534-559.

Sariannidis, N., Giannarakis, G., Litinas, N., \& Konteos, G. (2010). A garch examination of macroeconomic effects on U.S. Stock Market: a distinction between the total market index and the sustainability index. European Research Studies, 13(1). 
Sawani, Y., Zain, M., \& Darus, F. (2010). Preliminary insights on sustainability reporting and assurance practices in Malaysia. Social Responsibility Journal, 6(4), 627-645.

Schaeffer, R., Borba, B. S. M. C., Rathmann, R., Szklo, A., \& Castelo Branco, D. A. (2012). Dow Jones sustainability index transmission to oil stock market returns: A garch approach. Energy, 45(1), 933-943.

Searcy, C., \& Elkhawas, D. (2012). Corporate sustainability ratings: an investigation into how corporations use the Dow Jones Sustainability Index. Journal of Cleaner Production, 35, 79-92.

Skare, M., \& Golja, T. (2012). Corporate social responsibility and corporate financial performance - is there a link? Economic Research. 25(SE1), 215-242.

Sparkes, R. (2002). Socially responsible investment: a global revolution. Nova Iorque: Wiley. Swidler, S., \& Crutchley, C. E. (2009). Do corporate boards care about sustainability? Should they care? In Corporate boards: managers of risk, sources of risk (R. W. Kolb \& D. Schwartz, Eds.) Oxford: Blackwell Publishing, 217-234.

Tsoutsoura, M. (2004). Corporate social responsibility and financial performance. Berkeley: center for responsible business (Working Paper Series). Berkeley, CA: Haas School of Business.

Vogel, D. (2006). The market for virtue: the potential and limits of corporate social responsibility. Brookings Institution Press.

Wernerfelt, B. (1984). A resource-based view of the firm. Ann Arbor: Strategic Management Journal, 5, 171-180.

Yu, M., \& Zhao, R. (2015). Sustainability and firm valuation: an international investigation. International Journal of Accounting and Information Management, 23(3), 289-307.

Ziegler, A. (2012). Is it beneficial to be included in a sustainability stock Index? A panel data study for european firms. Environmental Resource Economics, 52(3), 301-325.

Data da submissão: 21/02/2017

Data de aceite: 06/06/2017 